06,05

\title{
Мультиферроидные свойства и структурные особенности Al-замещенных гексаферритов бария $M$-типа
}

\author{
(C) А.В. Труханов ${ }^{1,2}$, С.В. Труханов ${ }^{1,2}$, В.Г. Костишин ${ }^{1}$, Л.В. Панина ${ }^{1}$, М.М. Салем ${ }^{1}$, \\ И.С. Казакевич ${ }^{2}$, В.А. Турченко ${ }^{3,4}$, В.В. Кочервинский ${ }^{5}$, Д.А. Кривченя ${ }^{2}$ \\ ${ }^{1}$ Национальный исследовательский технологический университет „МИСиС“, \\ Москва, Россия \\ ${ }^{2}$ НПЦ НАН Беларуси по материаловедению, \\ Минск, Беларусь \\ ${ }^{3}$ Лаборатория нейтронной фризики им. И.М. Франка, Объединенный институт ядерных исследований, \\ Дубна, Россия \\ ${ }^{4}$ Донецкий фризико-технический институт им. А.А. Галкина, \\ Донецк, Украина \\ ${ }^{5}$ Филиал Научно-исследовательского фризико-химического института им. Л.Я. Карпова, \\ Москва, Россия \\ E-mail: truhanov86@mail.ru
}

(Поступила в Редакцию 10 августа 2016 г.)

Выполнены прецизионные исследования кристаллической и магнитной структуры замещенных гексаферритов бария $M$-типа $\mathrm{BaFe}_{12-x} \mathrm{Al}_{x} \mathrm{O}_{19}(0.1 \leq x \leq 1.2)$ методом порошковой дифракции нейтронов в интервале температур 300-730 K. Исследованы электрическая поляризация и намагниченность, а также магнитоэлектрический эффект рассматриваемых составов в электрическом (до $110 \mathrm{kV} / \mathrm{m}$ ) и магнитном (до $14 \mathrm{~T}$ ) полях при комнатной температуре. Установлено сохранение коллинеарной ферримагнитной структуры с замещением. Обнаружено наличие спонтанной поляризации и сильной взаимосвязи диэлектрической и магнитной подсистем при комнатной температуре. Величина магнитоэлектрического эффекта составляет в среднем около $5 \%$, несколько увеличиваясь с ростом концентрации катионов алюминия. Прецизионные структурные исследования позволили установить причину и механизм возникновения спонтанной поляризации в замещенных гексаферритах бария $M$-типа $\mathrm{BaFe}_{12-x} \mathrm{Al}_{x} \mathrm{O}_{19}(x \leq 1.2)$ с коллинеарной ферримагнитной структурой.

Работа выполнена при софинансировании Министерства образования и науки РФ по программе повышения конкурентоспособности НИТУ „МИСиС“ среди ведущих мировых научно-образовательных центров (№ К4-2015-040 и К3-2016-019) и при поддержке грантов БРФФИ (№ Ф15Д-003) и ОИЯИ (№ 04-4-1121-2015/2017). Л.В. Панина благодарит правительство РФ за поддержку в рамках государственного заказа по организации научной работы.

DOI: $10.21883 / F T T .2017 .04 .44274 .328$

\section{1. Введение}

До недавнего времени феррит бария с гексагональной структурой магнетоплюмбита ( $M$-тип) $\mathrm{BaFe}_{12} \mathrm{O}_{19}$ широко использовался только в качестве постоянных магнитов [1] и в магнитных носителях записи информации высокой плотности с перпендикулярным намагничиванием [2]. Однако в последнее время гексаферрит бария $M$-типа привлекает все большее внимание как мультиферроик - материал, проявляющий существенную взаимосвязь магнитных и диэлектрических свойств $[3,4]$. Такие материалы найдут широкое применение в новом направлении микроэлектроники - спинтронике [5].

Для практических задач спинтроники, в частности для создания электрически управляемых магнитов, требуются мультиферроики с большими значениями намагниченности и коэрцитивной силы в области комнатных температур. Характерно, что известные сегодня высокотемпературные мультиферроики обладают слабыми магнитными свойствами. Так, один из интенсивно исследуемых в настоящее время мультиферроиков перовскитный феррит висмута $\mathrm{BiFeO}_{3}$ - обладает серьезным недостатком. Он характеризуется несоразмерной пространственно-модулированной магнитной структурой циклоидного типа, из-за чего линейный магнитоэлектрический эффект отсутствует, а проявляется только менее интенсивный квадратичный [5]. Поэтому претендентами на роль мультиферроиков, перспективных для применения при комнатной температуре, могут быть соединения, созданные на базе гексагональных ферритов.

Гексаферриты обладают довольно сложной кристаллической структурой, которая представляется в виде некоторой последовательности шпинельных и гексагональных блоков, чередующихся вдоль оси $c$ и содержащих довольно большое число катионов железа [6]. Среди большого числа типов гексаферритов с различными кристаллическими структурами простейшим является $M$-тип. Модель магнитной структуры бариевых гексаферритов $M$-типа, предложенная Гортером [7], 
предполагает, что для одной формульной единицы магнитоактивные катионы $\mathrm{Fe}^{3+}$ расположены в пяти неэквивалентных кристаллографических позициях, которые имеют октаэдрическое $\left(\mathrm{Fe} 1-2 a, \mathrm{Fe} 4-4 f_{\text {VI }}, \mathrm{Fe} 5-\right.$ $12 k)$, пентаэдрическое (бипирамидальное) $(\mathrm{Fe} 2-2 b)$ и тетраэдрическое $\left(\mathrm{Fe} 3-4 f_{\mathrm{IV}}\right)$ кислородное окружение. Ниже температуры Кюри 740 K [1] двенадцать катионов $\mathrm{Fe}^{3+}$, образующие пять магнитных подрешеток, упорядочиваются антипараллельно $(1 \cdot \mathrm{Fe} 1 \uparrow, 2 \cdot \mathrm{Fe} 2 \downarrow, 1 \cdot \mathrm{Fe} 3 \uparrow$, $2 \cdot \mathrm{Fe} 4 \downarrow$, $6 \cdot \mathrm{Fe} 5 \uparrow)$ и при $0 \mathrm{~K}$ дают суммарный магнитный момент, равный $20 \mu_{\mathrm{B}}$ на одну формульную единицу [8].

Впервые спонтанная поляризация в исходном поликристаллическом $\mathrm{BaFe}_{12} \mathrm{O}_{19}$ при комнатной температуре была зафиксирована недавно в работе [4], а более интенсивные мультиферроидные свойства - чуть позже (в образцах, полученных по модифицированной керамической технологии в работах $[9,10])$. Еще раньше магнитоэлектрический эффект, хотя и более слабый, при комнатной температуре был обнаружен в Sc-замещенных монокристаллах $\mathrm{BaFe}_{12-x} \mathrm{Sc}_{x} \mathrm{Mg}_{\delta} \mathrm{O}_{19}(x=1.6,1.7 ; \delta=0.05)$ [3] и $(x=1.3-1.7 ; \delta=0)$ [11]. Хотя замещенные и исходные образцы имеют почти идентичные химический состав и кристаллическую структуру, наличие спонтанной поляризации было интерпретировано для них поразному.

Обе группы гексаферритов относятся к мультиферроикам типа II, т.е. зарядовое упорядочение ионов $\mathrm{O}^{2-}$ и $\mathrm{Fe}^{3+}$ является следствием существования магнитного упорядочения [12]. И если для замещенных гексаферритов поляризация объясняется спонтанным переходом из коллинеарной ферримагнитной одноосной фазы в конусную структуру при понижении температуры $[3,11]$, то для исходных образцов такое объяснение невозможно. Для последних объяснение найдено в искажении кислородного октаэдра $[4,9,10]$, однако подробной структурной информации не приведено.

Наибольший интерес у исследователей гексаферритов вызывает случай диамагнитных замещений [13-15]. Замещение ионов железа диамагнитными ионами может приводить к увеличению спонтанной намагниченности в зависимости от предпочтения занимаемых ими кристаллографических позиций [16] и увеличению спонтанной поляризации в случае образования пустыми $d$-оболочками сильной несимметричной ковалентной связи с окружающими анионами кислорода [17]. Такое замещение также может приводить к конкуренции обменных взаимодействий и возникновению конусных магнитных структур [18]. Кроме того, замещение малыми количествами диамагнитных катионов способно значительно повысить удельное электросопротивление гексаферрита $[3,11]$. Существенная роль величины удельного электросопротивления при регистрации магнитоэлектрического эффекта в магнитных материалах отмечается во многих работах [19]. К образованию неколлинеарной магнитной структуры может приводить также наномасштабное фазовое расслоение [20].

Цель настоящей работы состоит в поиске новых интенсивных мультиферроиков, перспективных для при- менения при комнатной температуре, и уточнении механизма спонтанной поляризации в гексаферритах бария $M$-типа, замещенных диамагнитными катионами алюминия $\left(\mathrm{BaFe}_{12-x} \mathrm{Al}_{x} \mathrm{O}_{19}, x \leq 1.2\right)$. Недавно нами уже были исследованы структура и магнитные свойства гексаферритов бария, замещенных катионами алюминия, при комнатной температуре [21-24]. Одним из методов, использованных в настоящей работе, является метод порошковой дифракции нейтронов, основным достоинством которого является комплексность анализа. В одном эксперименте была получена информация об изменениях как кристаллической, так и магнитной структуры, а также данные о поведении микроструктуры образца. Данная информация позволила внести ясность в механизм формирования ферроэлектрических свойств гексаферритов.

\section{2. Методика эксперимента}

Поликристаллические образцы твердых растворов $\mathrm{BaFe}_{12-x} \mathrm{Al}_{x} \mathrm{O}_{19}$ были получены из оксидов $\mathrm{Fe}_{2} \mathrm{O}_{3}, \mathrm{Al}_{2} \mathrm{O}_{3}$ и карбоната $\mathrm{BaCO}_{3}$ (все квалификации ОСЧ), взятых в строго стехиометрическом соотношении. Расчеты масс составных компонентов образцов и формирование навесок производились в соответствии со стехиометрическим соотношением общего уравнения реакции

$$
\begin{gathered}
\mathrm{BaCO}_{3}+\{(12-x) / 2\} \cdot \mathrm{Fe}_{2} \mathrm{O}_{3}+\{x / 2\} \cdot \mathrm{Al}_{2} \mathrm{O}_{3} \\
\rightarrow \mathrm{BaFe}_{12-x} \mathrm{Al}_{x} \mathrm{O}_{19}+\mathrm{CO}_{2} \uparrow .
\end{gathered}
$$

Смешанные в стехиометрическом соотношении порошки подвергались мокрому помолу с добавлением этилового спирта на шаровой мельнице в течение $2 \mathrm{~h}$. После помола и сушки исходные смеси порошков прессовались на гидравлическом прессе в цилиндрической форме (диаметр $10 \mathrm{~mm}$, высота $5 \mathrm{~mm}$ ). Компактированные составы подвергались синтезирующему обжигу на воздухе при $1200^{\circ} \mathrm{C}$ в течение $6 \mathrm{~h}$, а затем (после промежуточного помола) - в течение $0.5 \mathrm{~h}$, образцы вновь компактировались и спекались при $1200^{\circ} \mathrm{C}$ в течение $3 \mathrm{~h}$. После спекания образцы медленно охлаждались со скоростью $\sim 100^{\circ} \mathrm{C} / \mathrm{h}$.

Методика исследования морфологии образцов дана в [23]. Предварительный структурный и качественный фазовый анализ полученных образцов был проведен при комнатной температуре на рентгеновском дифрактометpe ДРОН-3М в $\mathrm{Cu} K_{\alpha}$-излучении с шагом сканирования $0.05^{\circ}$.

Прецизионное исследование кристаллической и магнитной структур было выполнено методом порошковой дифракции нейтронов в широком диапазоне температур от 300 до $730 \mathrm{~K}$ на Фурье-дифрактометре высокого разрешения (ФДВР) [25]. ФДВР представляет собой времяпролетный дифрактометр на импульсном реакторе ИБР-2М (Дубна) с относительно большой $(\sim 21.131 \mathrm{~m})$ пролетной базой от замедлителя до детектора и обладает исключительно высокой разрешающей способностью 

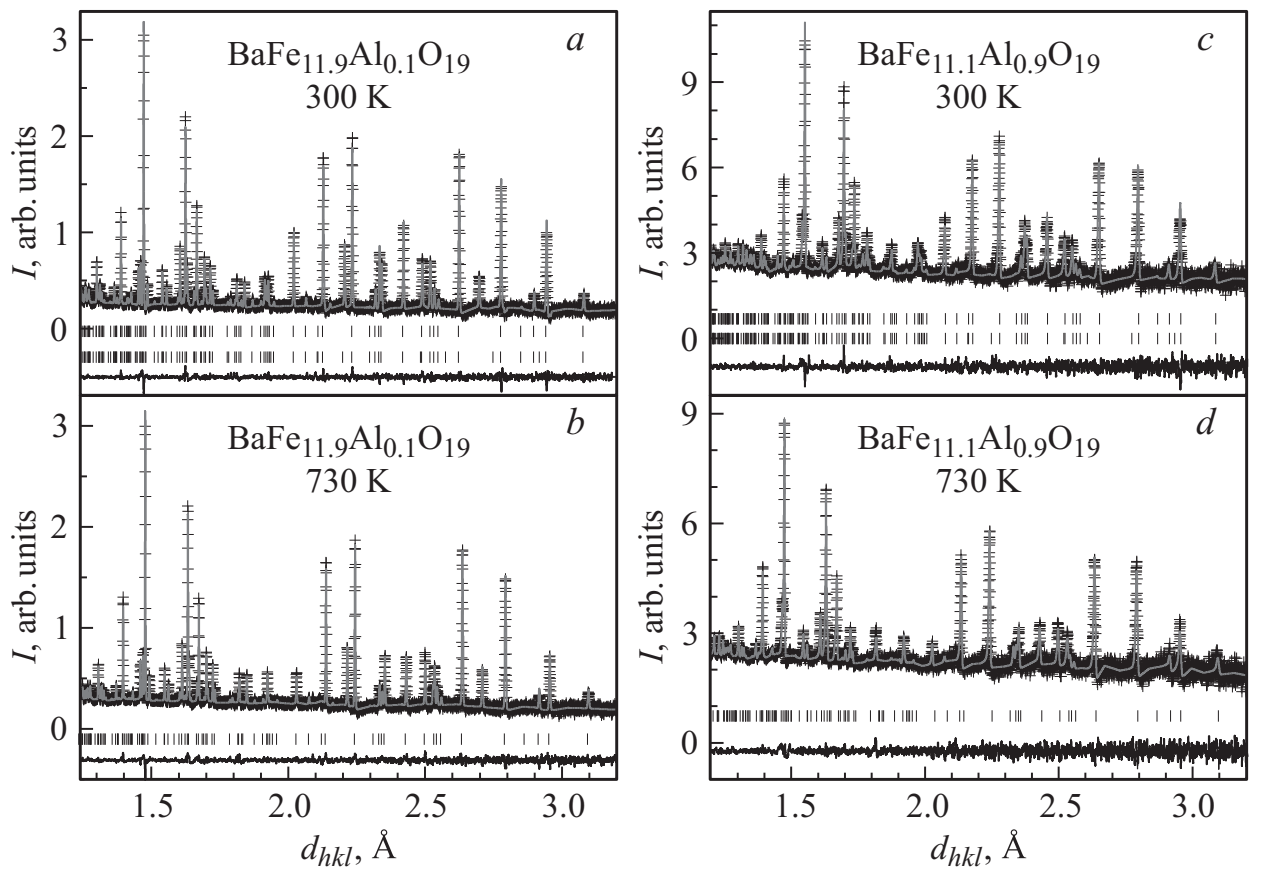

Рис. 1. Общий вид нейтронограмм гексаферрита $\mathrm{BaFe}_{12-x} \mathrm{Al}_{x} \mathrm{O}_{19} \mathrm{c} x=0.1(a, b)$ и $0.9(c, d)$, измеренных на ФДВР при комнатной $(300 \mathrm{~K})(a, c)$ и высокой $(730 \mathrm{~K})(b, d)$ температурах и обработанных по методу Ритвельда. Пояснения даны в тексте.

$(\Delta d / d \approx 0.001)$, которая практически не зависит от межплоскостного расстояния в широком интервале $d_{h k l}$. Нейтронограммы высокого разрешения измерялись детекторами, расположенными при средних углах рассеяния $\pm 152^{\circ}$, в интервале межплоскостных расстояний от 0.6 до $3.6 \AA$.

Расчет экспериментальных времяпролетных нейтронограмм выполнялся методом полнопрофильного анализа Ритвельда [26] с помощью программных пакетов MRIA и FullProf [27] с использованием встроенных таблиц для длин когерентного рассеяния и магнитных формфакторов. Разрешение ФДВР определялось в ходе отдельного эксперимента по эталону $\mathrm{Al}_{2} \mathrm{O}_{3}$ при комнатной температуре. Параметры микроструктуры определялись по уширению отдельных дифракционных пиков.

Высоковольтная электрическая поляризация измерялась при температуре $300 \mathrm{~K}$ с помощью установки, детали которой описаны в работе [28]. Использовалась конфигурация электрического поля в виде биполярных импульсов (пилообразного биполярного напряжения), подаваемых на измеряемый конденсатор. Для проведения измерения электрической поляризации применялись электроды на основе серебряной пасты. Электрический отклик регистрировался с помощью высокоомного операционного усилителя, данные с которого через аналогоцифровой преобразователь фиксировались с помощью персонального компьютера. Перед измерением образцы подвергались закорачиванию.

Исследования удельной намагниченности были выполнены с помощью универсальной криогенной высокополевой измерительной системы (Liquid Helium Free High Field Measurement System by Cryogenic Ltd, London, UK) при температуре $300 \mathrm{~K}$ в полях до $14 \mathrm{~T}$ [29]. Магнитные измерения проводились на поликристаллических образцах со средним размером $2 \times 3 \times 5 \mathrm{~mm}$. Спонтанная намагниченность определялась по полевой зависимости линейной экстраполяцией к нулевому полю. Для проведения измерения удельной намагниченности в постоянном электрическом поле использовались электроды на основе серебряной пасты. В качестве источника тока применялся „Source Meter Keithley 2400“. Направление электрического поля было перпендикулярно направлению магнитного поля $(\mathbf{E} \perp \mathbf{B})$. Магнитоэлектрический коэффициент рассчитывался по формуле

$$
K_{\mathrm{me}}=M_{s}(0)-M_{s}(E) / M_{s}(0) \cdot 100 \%,
$$

где $M_{s}(0)$ - спонтанная намагниченность в нулевом внешнем электрическом поле, $M_{x}(E)-$ спонтанная намагниченность во внешнем электрическом поле $60 \mathrm{kV} / \mathrm{m}$.

\section{3. Экспериментальные результаты и их обсуждение}

3.1. Кристаллическая структура. Синтезированные образцы гексаферрита бария, замещенного катионами алюминия $\left(\mathrm{BaFe}_{12-x} \mathrm{Al}_{x} \mathrm{O}_{19} 0.1 \leq x \leq 1.2\right)$, представляли собой керамику с плотностью выше 98\% и средним размером кристаллита $\sim 1 \mu \mathrm{m}$ [23]. Для описания кристаллической структуры была использована пространственная группа P63/mmc (№ 194). Высокая разрешающая способность ФДВР позволила выполнить прецизионное уточнение атомной структуры и определение параметров кристаллической решетки. Примеры 


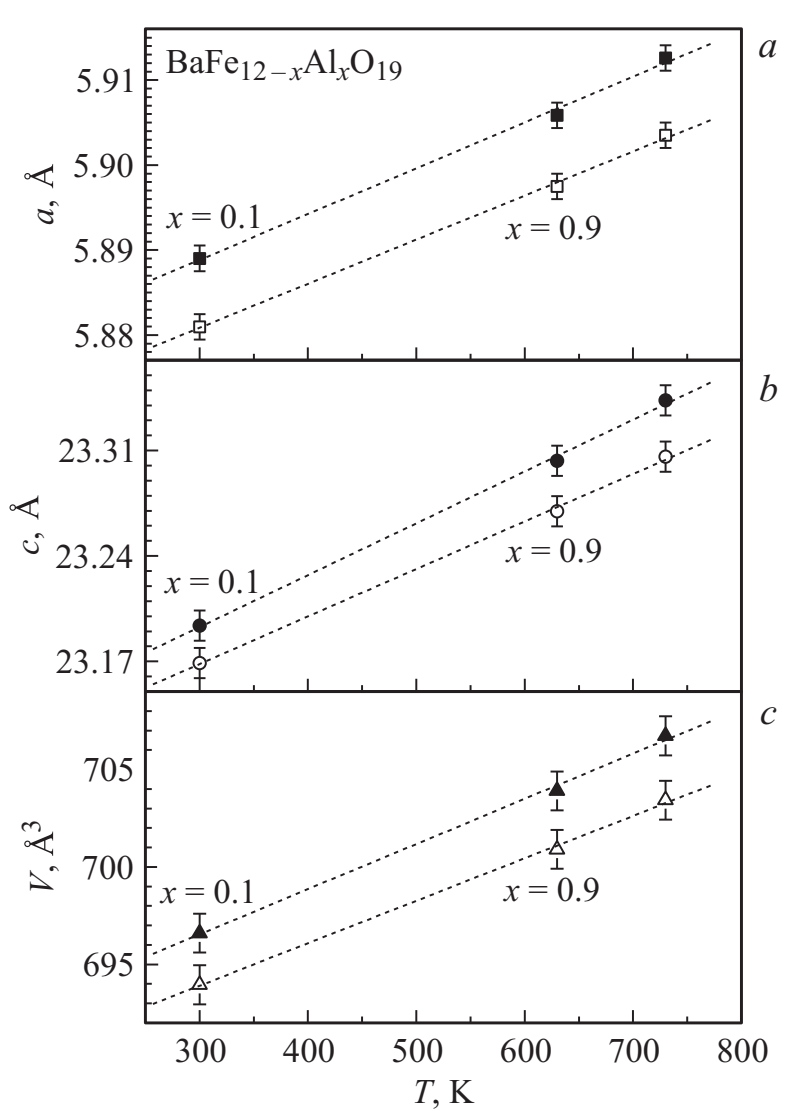

Рис. 2. Температурные зависимости параметров $a(a), c(b)$ и объема $V(c)$ элементарной ячейки для гексаферрита $\mathrm{BaFe}_{12-x} \mathrm{Al}_{x} \mathrm{O}_{19}$ с $x=0.1$ (темные символы) и 0.9 (светлые символы).

нейтронограмм, полученных при комнатной $(300 \mathrm{~K})$ и высокой $(730 \mathrm{~K})$ температуре и обработанных по методу Ритвельда для образцов с $x=0.1$ и 0.9 , приведены на рис. 1. Большое число хорошо разделенных пиков обеспечило хорошую сходимость процесса минимизации. В расчете учитывались тепловые колебания атомов в изотропном приближении, магнитная структура гексаферрита в коллинеарном приближении. На рис. 1 показаны экспериментальные точки (крестики), расчетная кривая (верхняя линия) и разностная функция (нижняя линия), нормированная на статистическую ошибку. Вертикальными штрихами обозначены рассчитанные положения дифракционных пиков для кристаллической и магнитной структур бариевого гексаферрита. На нейтронограмме, измеренной при $730 \mathrm{~K}$, магнитной фазы нет.

Параметры и объем элементарной ячейки с ростом температуры увеличивались почти линейно (рис. 2). Для образца с $x=0.1$ параметр а возрастал от $5.889 \AA$ $(300 \mathrm{~K})$ до $5.912 \AA(730 \mathrm{~K})$. Параметр $c$ увеличивался от $23.194 \AA(300 \mathrm{~K})$ до $23.343 \AA(730 \mathrm{~K})$. Объем $V$ возрастал от $696.61 \AA(300 \mathrm{~K})$ до $706.73 \AA(730 \mathrm{~K})$. С ростом концентрации катионов алюминия соответствующие параметры несколько уменьшались. Так, для образца с $x=0.9$ параметр $a$ возрастал от $5.881 \AA$
$(300 \mathrm{~K})$ до $5.904 \AA(730 \mathrm{~K})$. Параметр $c$ - от $23.169 \AA$ $(300 \mathrm{~K})$ до $23.306 \AA(730 \mathrm{~K})$, а объем $V-$ от $693.96 \AA$ $(300 \mathrm{~K})$ до $703.43 \AA(730 \mathrm{~K})$. Такое поведение параметров элементарной ячейки объясняется увеличением энергии теплового колебания катионов для фиксированной концентрации катионов алюминия, а также уменьшением среднего ионного радиуса подрешетки железа с ростом концентрации катионов алюминия.

Хорошо известно, что катион железа обладает бо́льшим ионным радиусом, чем катион алюминия, для одной и той же валентности и координации [30]. В исследованном температурном интервале структурных превращений не было обнаружено ни для одного из образцов. Коэффициенты теплового расширения зависят от направления и составляют $\alpha_{a}=5.35 \cdot 10^{-5} \mathrm{~K}^{-1}$ $(x=0.1 \quad$ и 0.9$)$ и $\alpha_{c}=3.47 \cdot 10^{-4} \mathrm{~K}^{-1} \quad(x=0.1)$ и $\alpha_{c}=3.19 \cdot 10^{-4} \mathrm{~K}^{-1}(x=0.9)$ в интервале $300-730 \mathrm{~K}$.

Согласно результатам наших структурных исследований, наиболее высокая вероятность расположения замещающих катионов алюминия в октаэдрических кристаллографических позициях $\mathrm{Fe} 5(12 k)$. Такой результат хорошо согласуется с выводами теоретической работы [31], в которой на основе расчета энергий образования дефектов показано предпочтительное заполнение катионами $\mathrm{Al}^{3+}$ октаэдрических кристаллографических позиций $\mathrm{Fe} 1(2 a)$ и $\mathrm{Fe} 5(12 k)$ в гексаферрите бария $M$-типа $\mathrm{BaFe}_{12-x} \mathrm{Al}_{x} \mathrm{O}_{19}(0.5 \leq x \leq 1.2)$. Более подробная информация о кристаллической структуре рассматриваемых образцов дана в работах [21-24].

3.2. Магнитная структура. На нейтронограммах, полученных при комнатной температуре, наблюдалось только увеличение интенсивности существующих ядерных рефлексов и отсутствовали дополнительные рефлексы. Такая картина указывает на наличие коллинеарной магнитной структуры при комнатной температуре. Низкие значения величины $\chi^{2}=1.61-1.92$ и других параметров соответствия: $R_{\mathrm{wp}}=10.92-13.56$, $R_{\exp }=4.56-8.63, R_{\operatorname{mag}}=17.31-19.52-$ указывают на хорошее согласие расчетной модели и эксперимента. Следует особо отметить, что использование модели с неколлинеарной магнитной структурой не привело к уменьшению параметров соответствия по сравнению с коллинеарной моделью. На этом основании можно утверждать, что синтезированные образцы гексаферрита бария, замещенного катионами алюминия $\left(\mathrm{BaFe}_{12-x} \mathrm{Al}_{x} \mathrm{O}_{19}, 0.1 \leq x \leq 1.2\right)$, обладают коллинеарной магнитной струтурой.

Для рассматриваемых гексаферритов при переходе через $T_{c}$ магнитные пики накладываются на структурные. Несмотря на ферримагнитную структуру, в данном случае волновой вектор $k=[0,0,0]$, что указывает на совпадение кристаллической и магнитной структур. Поэтому магнитная составляющая влияет только на интенсивность пиков, причем магнитные пики сильнее проявляются при больших $d_{h k l}$, а при уменьшении значений $d_{h k l}$ их вклад существенно уменьшается. Если бы наблюдалось отклонение от коллинеарной одноосной ферримагнитной структуры, то на нейтронограммах 

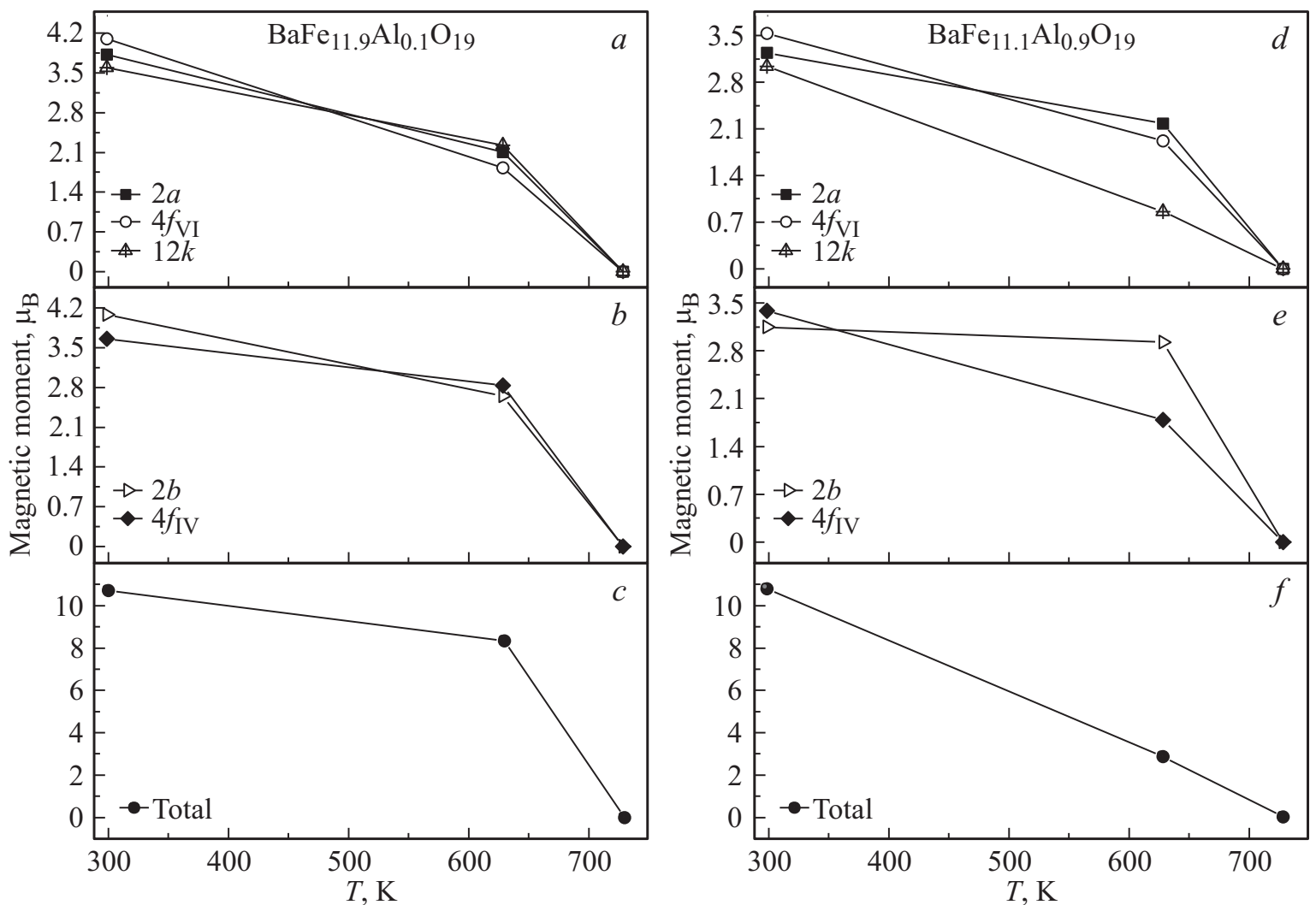

Рис. 3. Температурные зависимости магнитных моментов ионов железа в кристаллографических позициях $2 a, 2 b, 4 f$ IV, $4 f_{\mathrm{VI}}, 12 k$ и суммарный магнитный момент (total), рассчитанные в программе FullProf для образцов $\mathrm{BaFe}_{11.9} \mathrm{Al}_{0.1} \mathrm{O}_{19}(a-c)$ и $\mathrm{BaFe}_{11.1} \mathrm{Al}_{0.9} \mathrm{O}_{19}(d-f)$.

появлялись бы дополнительные пики, не связанные со структурными, при переходе в магнитоупорядоченное состояние. Однако никаких дополнительных пиков не наблюдается.

Для всех образцов $\mathrm{BaFe}_{12-x} \mathrm{Al}_{x} \mathrm{O}_{19} \quad(0.1 \leq x \leq 1.2)$ определен магнитный момент во всех неэквивалентных кристаллографических позициях (рис. 3). При $300 \mathrm{~K}$ для образца с $x=0.1$ магнитный момент для $\mathrm{Fe} 1(2 a)$ равен $3.822 \mu_{\mathrm{B}}$, для $\mathrm{Fe} 2(2 b)-4.072 \mu_{\mathrm{B}}$, для $\mathrm{Fe}_{3}\left(4 f_{\mathrm{IV}}\right)-3.654 \mu_{\mathrm{B}}$, для $\mathrm{Fe}_{4}\left(4 f_{\mathrm{VI}}\right)-4.092 \mu_{\mathrm{B}}$, для $\mathrm{Fe} 5(12 k)-3.590 \mu_{\mathrm{B}}$. В случае образца с $x=0.9$ магнитный момент для $\mathrm{Fe} 1(2 a)$ равен $3.244 \mu_{\mathrm{B}}$, для $\mathrm{Fe} 2(2 b)-3.144 \mu_{\mathrm{B}}$, для $\mathrm{Fe} 3\left(4 f_{\mathrm{IV}}\right)-3.389 \mu_{\mathrm{B}}$, для $\mathrm{Fe} 4\left(4 f_{\mathrm{VI}}\right)-3.530 \mu_{\mathrm{B}}$, для $\mathrm{Fe} 5(12 k)-3.036 \mu_{\mathrm{B}}$.

Отсюда следует, что диамагнитное замещение осуществляется в октаэдрическую позицию $\mathrm{Fe} 5(12 k)$. Суммарный магнитный момент всех пяти неэквивалентных позиций железа с учетом их ферримагнитного упорядочения при $300 \mathrm{~K}$ составляет $10.713 \mu_{\mathrm{B}}(x=0.1)$ и $10.766 \mu_{\mathrm{B}}(x=0.9)$. Следует отметить, что соответствующие магнитные моменты при одинаковых температурах уменьшаются с ростом концентрации катионов алюминия. Это указывает на ослабление внутриподрешеточного обменного взаимодействия.

3.3. Длины связей. Интересные особенности можно обнаружить при тщательном анализе изменения бли- жайших длин связи $\mathrm{Fe} i-\mathrm{O} j(1 \leq i, j \leq 5)$, представленных на рис. 4.

Для большинства неэквивалентных кристаллографических позиций длины связи между катионами железа и анионами кислорода возрастают с увеличением температуры, что ожидаемо ввиду увеличения энергии теплового колебания ионов. Однако можно выделить ряд характерных особенностей. Так, для фиксированного значения уровня замещения $x=0.9$ для тетраэдрической позиции $4 f_{\mathrm{IV}}$, пентаэдрической $2 b$ и октаэдрической $12 k$ наблюдается уменьшение некоторых длин связи, причем если для тетраэдрической позиции $4 f_{\text {IV }}$ обе длины связи $\mathrm{Fe} 3-\mathrm{O} 2$ и $\mathrm{Fe} 3-\mathrm{O} 4$ уменьшаются с ростом температуры (позиция уплотняется), то для пентаэдрической $2 b$ и октаэдрической $12 k$ наблюдается разнонаправленный характер изменения длин связи. Это указывает на нецентросимметричное, полярное искажение полиэдров. Так, для октаэдрической позиции $12 k$ с ростом температуры наблюдается увеличение длин связи $\mathrm{Fe} 5-\mathrm{O} 1, \mathrm{Fe} 5-\mathrm{O} 2$ и $\mathrm{Fe} 5-\mathrm{O} 4$, в то время как длина связи $\mathrm{Fe} 5-\mathrm{O} 5$ уменьшается [32]. При уровне замещения $x=0.1$ число убывающих с ростом температуры длин связей меньше. Изменения в основном касаются пентаэдрической позиции $2 b$ : $\mathrm{Fe} 2-\mathrm{O} 1$ и $\mathrm{Fe} 2-\mathrm{O} 3$. Эти две длины связи меняют тип температурной зависимости на противоположный с ростом уровня замещения. Данный 

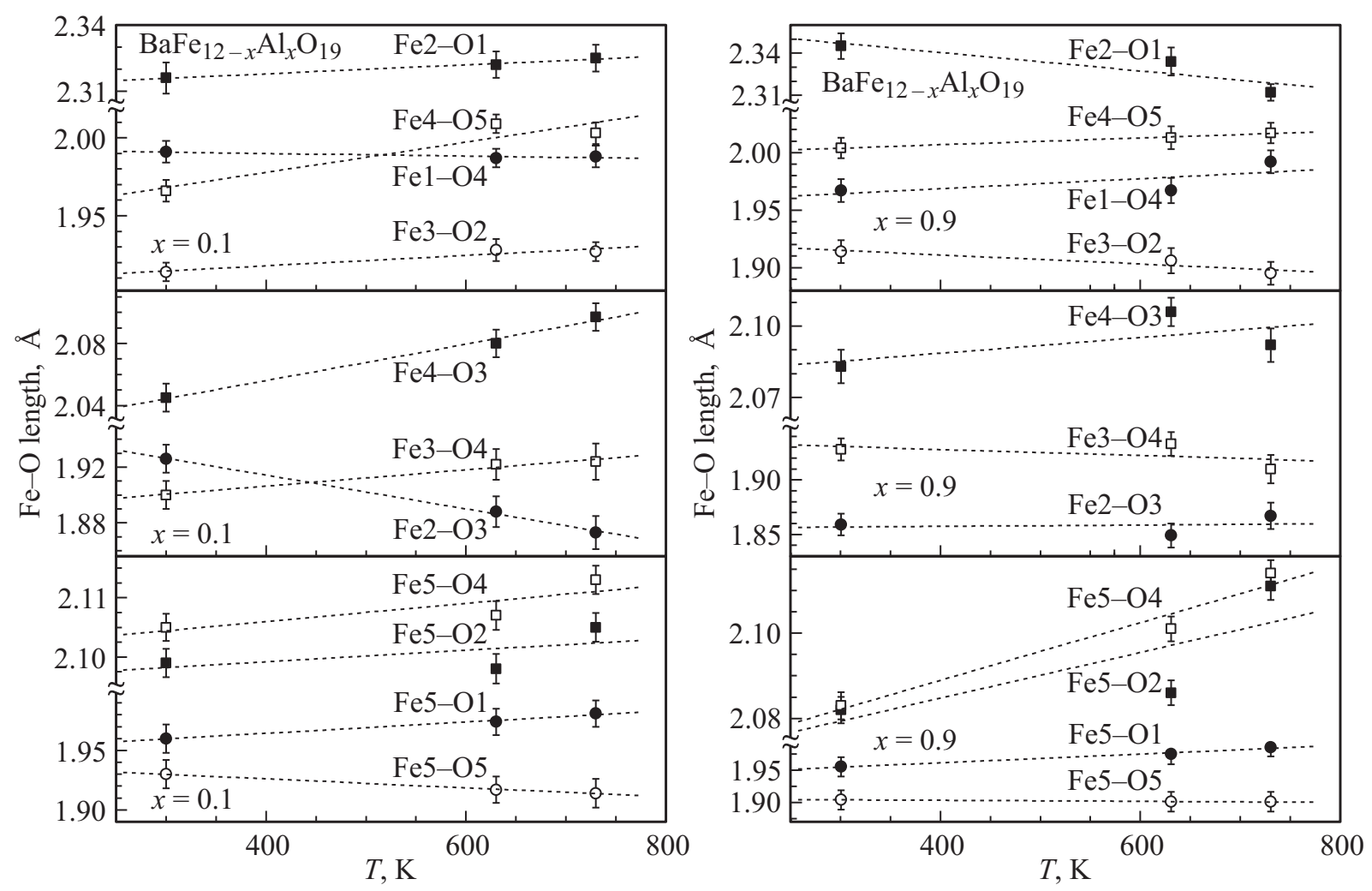

Рис. 4. Температурные зависимости ближайших длин связи $\mathrm{Fe} i-\mathrm{O} j(1 \leq i, j \leq 5)$ для гексаферрита $\mathrm{BaFe}_{12-x} \mathrm{Al}_{x} \mathrm{O}_{19}$ с $x=0.1$ (слева) и 0.9 (справа).

факт указывает на существенное влияние уровня замещения на полярное искажение полиэдров.

Таким образом, результаты нейтронографических исследований указывают на наличие в структуре замещенных гексаферритов $M$-типа $\mathrm{BaFe}_{12-x} \mathrm{Al}_{x} \mathrm{O}_{19}(0.1 \leq x 1.2)$ нецентросимметрично-искаженного, полярного октаэдра вокруг позиции $\mathrm{Fe} 5(12 k)$. Этот факт может быть следствием как существования коллинеарной ферримагнитной структуры, так и образования пустыми $d$-оболочками катиона $\mathrm{Al}^{3+}$ сильной несимметричной ковалентной связи с окружающими анионами кислорода.

3.4. Диэлектрическая поляризация. На рис. 5 представлены петли электрического гистерезиса поляризации при комнатной температуре для образцов $\mathrm{BaFe}_{12-x} \mathrm{Al}_{x} \mathrm{O}_{19}(x=0.1$ и 0.9$)$. Максимальное значение электрического поля, которого удалось достичь без возникновения электрического пробоя, составило $110 \mathrm{kV} / \mathrm{m}$. В этом поле спонтанная поляризация для образца с $x=0.9$ равнялась $5.8 \mathrm{mC} / \mathrm{m}^{2}$.

Это значение спонтанной поляризации приблизительно на два порядка меньше значения, полученного в работах $[4,9,10]$, и на три порядка больше, чем в работах $[3,11]$. Причиной такого результата являлись существенные токи утечки, имеющие место из-за низкого удельного электросопротивления образцов. В работах $[9,10]$ достигались максимальные электрические поля, приблизительно в 3 раза бо́льшие. Поскольку при регистрации поляризации в магнитных материалах существенную роль играет величина удельного электросопротивления, модификацией технологии получения образцов в будущем можно добиться ее значительного увеличения [9]. В поле $110 \mathrm{kV} / \mathrm{m}$ спонтанная поляризация для образца с $x=0.1$ равнялась $5.1 \mathrm{mC} / \mathrm{m}^{2}$. С возрастанием уровня замещения $x$ от 0.1 до 1.2 величина спонтанной поляризации увеличивалась приблизительно на $10 \%$.

С целью получения мелкозернистой структуры и высокоомной прослойки между зернами необходимо после операции сухого помола в шихту получаемой гексаферритовой керамики добавлять оксид бора в количестве 0.5 wt.\%. $\mathrm{B}_{2} \mathrm{O}_{3}$, который имеет температуру плавления $450^{\circ} \mathrm{C}$, в процессе нагрева шихты преобразуется в жидкость и, „обволакивая“ частицы образующихся зерен, ограничивает их рост, делая структуру мелкозернистой. Являясь хорошим диэлектриком, оксид бора в виде прослоек существенно уменьшает электрическую проводимость между зернами и таким образом позволяет получать в гексаферритовой керамике высокое удельное сопротивление.

Следует согласиться с авторами работы [9], что существованию спонтанной поляризации способствуют фиксация $180^{\circ}$ доменных стенок на границах зерен гексаферрита, образованных диэлектрической прослойкой $\mathrm{B}_{2} \mathrm{O}_{3}$, и возникновение электрической поляризации в направлении, перпендикулярном поверхности искривленной стенки. Тем не менее принципиальным резуль- 


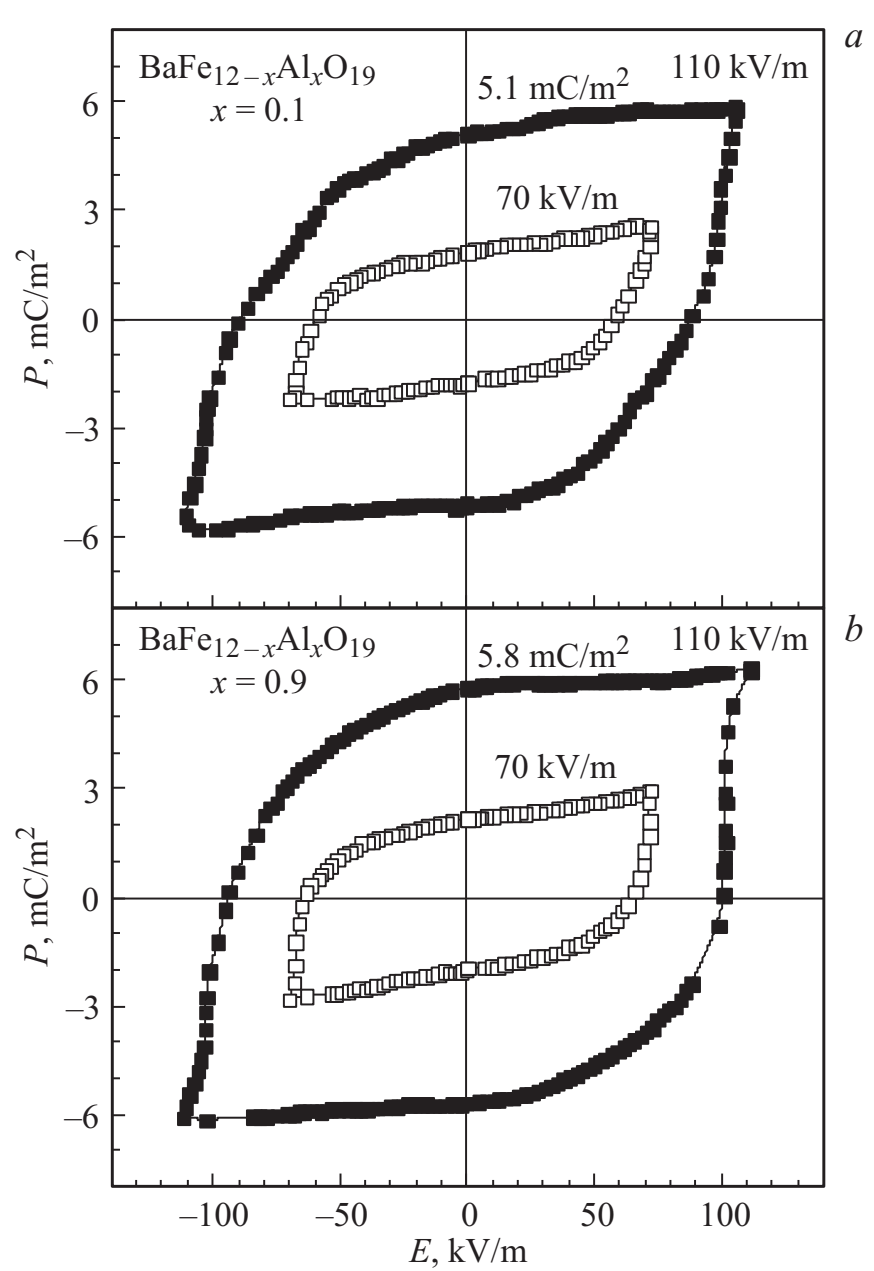

Рис. 5. Полевые зависимости диэлектрической поляризации, измеренные для максимальных значений электрического поля 70 и $110 \mathrm{kV} / \mathrm{m}$ при комнатной температуре $(300 \mathrm{~K})$ для гексаферрита $\mathrm{BaFe}_{12-x} \mathrm{Al}_{x} \mathrm{O}_{19}$ с $x=0.1$ (a) и $0.9(b)$.

татом нашего исследования является наличие ненулевой спонтанной поляризации.

С увеличением концентрации замещения катионами алюминия спонтанная поляризация немного (до 10\%) возрастает. Это связано с возрастанием концентрации пустых $d$-оболочек и образованием сильных несимметричных ковалентных связей в кристаллографической позиции $12 k$. Кроме того, так как катион $\mathrm{Al}^{3+}$ имеет ионный радиус меньше, чем катион $\mathrm{Fe}^{3+}$, увеличение концентрации замещения вызывает локальные искажения и микронапряжения кристаллической решетки. Это также способствует увеличению спонтанной поляризации. Говорить что-либо о величинах диэлектрической постоянной и тангенсе угла потерь, а также об их концентрационной, температурной и частотной зависимостях пока рано. Но, как следует из работы [33], с возрастанием концентрации замещения алюминием $x$ от 0.5 до 3.5 при комнатной температуре диэлектрическая постоянная и тангенс угла потерь убывают для одной и той же частоты переменного тока.
3.5. Магнитные свойства и магнитоэлектр ический эффект. На рис. 6 представлена полевая зависимость удельной намагниченности при комнатной температуре.

Исследуемые образцы характеризуются полем насыщения, приблизительно равным 2 Т [34]. Для образца с $x=0.9$ спонтанная намагниченность составила $22.7 \mathrm{emu} / \mathrm{g}$, что соответствует спонтанному атомному магнитному моменту $4.4 \mu_{\mathrm{B}} / \mathrm{f}$. u. При приложении внешнего электрического поля $60 \mathrm{kV} / \mathrm{m}$ спонтанная намагниченность возрастает примерно на 5\% до $23.9 \mathrm{emu} / \mathrm{g}$ $\left(4.8 \mu_{\mathrm{B}} /\right.$ f. u.). Эта величина магнитоэлектрического эффекта практически совпадает с величиной, полученной в работах $[9,10,32]$. Этот эффект может быть объяснен увеличением степени поляризации локальных спинов $\mathrm{Fe}^{3+}$ при добавлении в систему энергии электрического поля. Интересно заметить, что поликристалл на основе незамещенного $\mathrm{SrFe}_{12} \mathrm{O}_{19}$, полученного по аналогичной технологии, обладает примерно такой же величиной магнитоэлектрического эффекта [35]. Для образца с $x=0.1$ спонтанная намагниченность была больше и составила $52.6 \mathrm{emu} / \mathrm{g}$, что соответствует спонтанному атомному

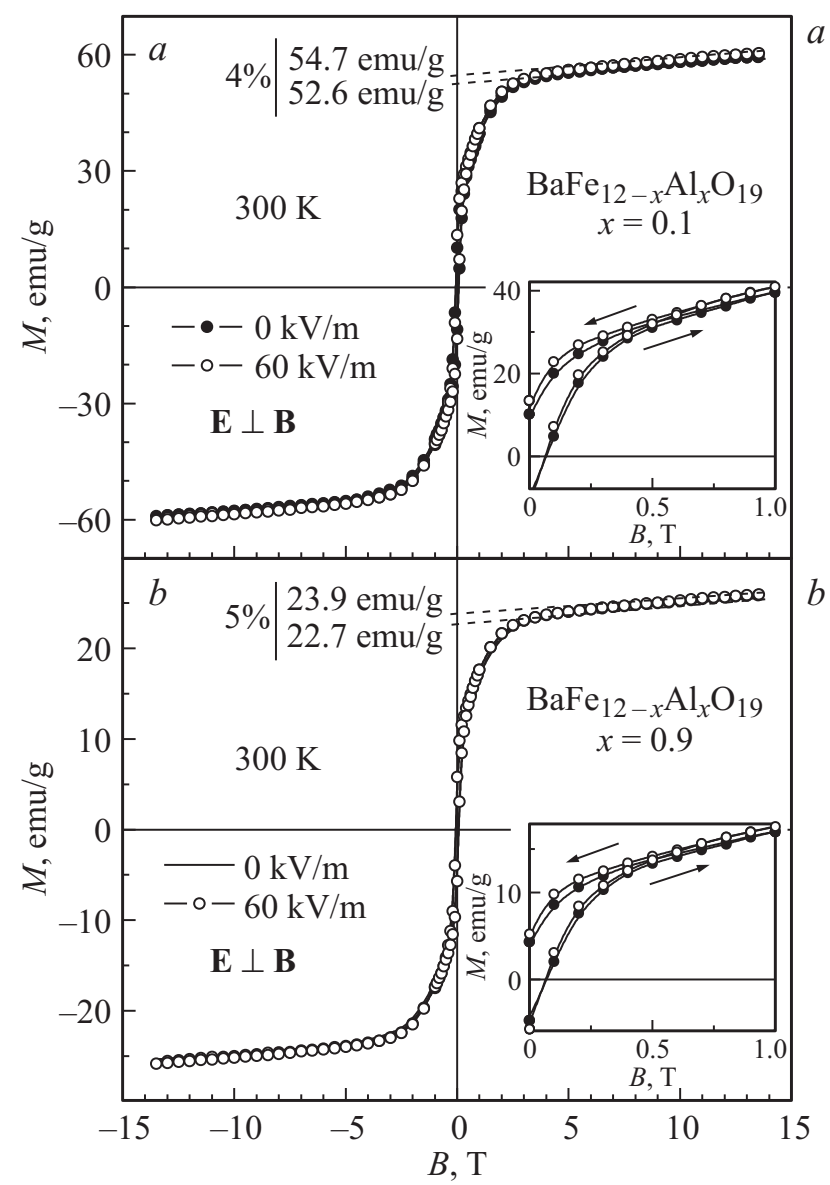

Рис. 6. Полевые зависимости удельной намагниченности, измеренные во внешнем электрическом поле $60 \mathrm{kV} / \mathrm{m}$ и без поля при комнатной температуре $(300 \mathrm{~K})$ для гексаферрита $\mathrm{BaFe}_{12-x} \mathrm{Al}_{x} \mathrm{O}_{19}$ с $x=0.1(a)$ и $0.9(b)$. Вставка демонстрирует изменение удельной намагниченности в увеличенном виде. 


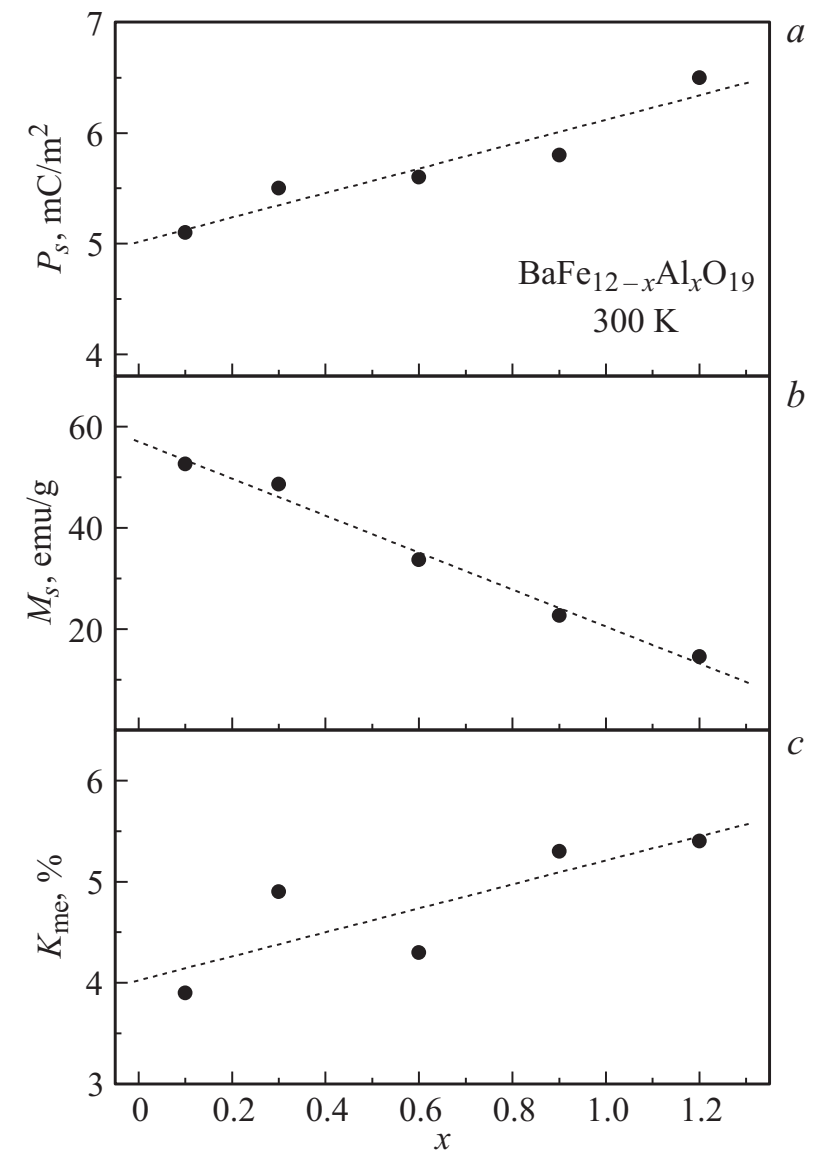

Рис. 7. Концентрационные зависимости спонтанной поляризации $(a)$, спонтанной намагниченности $(b)$ и магнитоэлектрического эффекта $(c)$ при комнатной температуре $(300 \mathrm{~K})$ для гексаферритов $\mathrm{BaFe}_{12-x} \mathrm{Al}_{x} \mathrm{O}_{19}(0.1 \leq x \leq 1.2)$.

магнитному моменту $10.4 \mu_{\mathrm{B}} /$ f. u. Во внешнем электрическом поле $60 \mathrm{kV} / \mathrm{m}$ спонтанная намагниченность возрастает примерно на $4 \%$ до $54.7 \mathrm{emu} / \mathrm{g}\left(11.1 \mu_{\mathrm{B}} / \mathrm{f}\right.$. u. $)$.

Концентрационные зависимости спонтанных поляризации и намагниченности, а также магнитоэлектрического коэффициента при комнатной температуре для образцов $\mathrm{BaFe}_{12-x} \mathrm{Al}_{x} \mathrm{O}_{19}(0.1 \leq x \leq 1.2)$ представлены на рис. 7.

Видно, что с ростом уровня замещения катионами алюминия спонтанная поляризация и магнитоэлектрический коэффициент немного возрастают, в то время как спонтанная намагниченность уменьшается. Это можно объяснить возрастанием концентрации пустых $d$-оболочек и образованием сильных несимметричных ковалентных связей в кристаллографической позиции $12 k$.

Вне всякого сомнения величина спонтанной поляризации, зависящая от электросопротивления образца, влияет на величину и точность измерения магнитоэлектрического эффекта. Величина поля пробоя ограничивает величину спонтанной поляризации, а также величину магнитоэлектрического эффекта в ненасыщенном состоянии. При достижении поляризации насыщения величина магнитоэлектрического эффекта не должна возрастать. Поскольку величина магнитоэлектрического эффекта, установленная в настоящей работе, практически совпадает с величиной, полученной в работах $[9,10]$, скорее всего, взаимосвязь спонтанной поляризации и магнитоэлектрического эффекта нелинейная.

Объяснить механизм возникновения спонтанной поляризации в замещенных гексаферритах $\mathrm{BaFe}_{12-x} \mathrm{Al}_{x} \mathrm{O}_{19}$ $(0.1 \leq x \leq 1.2)$ в данном случае формированием неколлинеарной магнитной структуры невозможно. Объяснение следует искать в зарядовом упорядочении. Идеальный центросимметричный кислородный октаэдр с малым катионом железа в центре характеризуется нулевым вектором поляризации. Нецентросимметричное, полярное искажение этого октаэдра, возникающее при смещении катиона железа к одному из анионов кислорода, приводит к появлению ненулевого дипольного электрического момента и, как следствие, к спонтанной поляризации.

\section{4. Заключение}

Таким образом, в результате выполнения настоящей работы получен новый класс мультиферроиков, перспективных для применения при комнатной температуре, на основе замещенных гексаферритов бария $M$-типа $\mathrm{BaFe}_{12-x} \mathrm{Al}_{x} \mathrm{O}_{19} \quad(0.1 \leq x \leq 1.2)$ с коллинеарной ферримагнитной структурой. Прецизионные структурные исследования позволили установить причину и механизм возникновения спонтанной поляризации при комнатной температуре в исследованных образцах. Поляризация является следствием нецентросимметричного, полярного искажения кислородного октаэдра вокруг катиона железа в кристаллографической позиции $12 k$. Искажение возникает при смещении катиона железа к одному из анионов кислорода, что приводит к появлению ненулевого дипольного электрического момента. Установлена также сильная взаимосвязь магнитной и диэлектрической подсистем в замещенных гексаферритах бария $M$-типа $\mathrm{BaFe}_{12-x} \mathrm{Al}_{x} \mathrm{O}_{19}(0.1 \leq x \leq 1.2)$. Эта взаимосвязь несколько усиливается с увеличением уровня замещения катионами алюминия.

\section{Список литературы}

[1] E. Richter, T.J.E. Miller, T.W. Neumann, T.L. Hudson. IEEE Transact. Industry Applications 21, 644 (1985).

[2] Q.A. Pankhurst, R.S. Pollard. J. Phys.: Condens. Matter. 5, 5457 (1993).

[3] Y. Tokunaga, Y. Kaneko, D. Okuyama, S. Ishiwata, T. Arima, S. Wakimoto, K. Kakurai, Y. Taguchi, Y. Tokura. Phys. Rev. Lett. 105, 257201 (2010).

[4] G. Tan, X. Chen. J. Magn. Magn. Mater. 327, 87 (2013).

[5] А.К. Звездин, А.П. Пятаков. УФН 174, 465 (2004).

[6] R.C. Pullar. Prog. Mater. Sci. 57, 1191 (2012).

[7] E.W. Gorter. Proc. IEEE Suppl. B 104, 225 (1957).

[8] J. Smit, H.P.J. Wijn. Ferrites. Cleaver, Hume Press, Ltd. (1959). $142 \mathrm{p}$. 
[9] В.Г. Костишин, Л.В. Панина, Л.В. Кожитов, А.В. Тимофеев, А.К. Зюзин, А.Н. Ковалев. ЖТФ 85, 8, 85 (2015).

[10] V.G. Kostishyn, L.V. Panina, A.V. Timofeev, L.V. Kozhitov, A.N. Kovalev, A.K. Zyuzin. J. Magn. Magn. Mater. 400, 327 (2016).

[11] А.М. Балбашов, В.Ю. Иванов, А.А. Мухин, Л.Д. Исхакова, Ю.Ф. Попов, Г.П. Воробьев, М.Е. Ворончихина. Письма в ЖЭТФ 101, 542 (2015).

[12] D.I. Khomskii. Physics 2, 20 (2009).

[13] О.П. Алешко-Ожевский, Р.А. Сизов, И.И. Ямзин. ЖЭТФ 55, 820 (1968).

[14] Н.Н. Ефимова, Ю.А. Мамалуй. ЖЭТФ 61, 1073 (1971).

[15] В.Ф. Белов, Т.А. Климич, М.Н. Шипко. ЖЭТФ 64, 2160 (1973).

[16] Ш.Ш. Башкиров, А.Б. Либерман, В.И. Синявский. ЖЭТФ 69, 1841 (1975).

[17] А.П. Пятаков, А.К. Звездин. УФН 182, 593 (2012).

[18] Т.М. Перекалина, М.А. Винник, Р.И. Зверева. ЖЭТФ 59, 1490 (1970).

[19] S. Katlakunta, P. Raju, S.S. Meena, S. Srinath, R. Sandhya, P. Kuruva, S.R. Murthy. Physica B 448, 323 (2014).

[20] С.Н. Зиненко, А.А. Мураховский, Л.П. Ольховик. ЖЭТФ 123, 1073 (2003).

[21] В.А. Турченко, А.В. Труханов, И.А. Бобриков, С.В. Труханов, А.М. Балагуров. Поверхность. Рентгеновские, синхротронные и нейтронные исследования 9, 21 (2015).

[22] В.А. Турченко, А.В. Труханов, И.А. Бобриков, С.В. Труханов, А.М. Балагуров. Кристаллография 60, 693 (2015).

[23] A.V. Trukhanov, V.O. Turchenko, I.A. Bobrikov, S.V. Trukhanov, I.S. Kazakevich, A.M. Balagurov. J. Magn. Magn. Mater. 393, 253 (2015).

[24] А.В. Труханов, Н.Т. Данг, С.В. Труханов, С.Г. Джабаров, И.С. Казакевич, А.И. Маммадов, Р.З. Мехдиева, В.А. Турченко, Р.Е. Гусейнов. ФТТ 58, 961 (2016).

[25] С.В. Труханов, И.О. Троянчук, А.В. Труханов, И.А. Бобриков, В.Г. Симкин, А.М. Балагуров. Письма в ЖЭТФ 84, 310 (2006).

[26] H.M. Rietveld. J. Appl. Cryst. 2, 65 (1969).

[27] http://www.ill.eu/sites/fullprof/

[28] В.В. Кочервинский, Е.В. Чубунова, Ю.Ю. Лебединский. Высокомолекуляр. соединения А 53, 1729 (2011).

[29] С.В. Труханов, А.В. Труханов, А.Н. Васильев, А.М. Балагуров, Н. Szymczak. ЖЭТФ 140, 942 (2011).

[30] R.D. Shannon. Acta Cryst. A 32, 751 (1976).

[31] A. Moitra, S. Kim, S.-G. Kim, S.C. Erwin, Y.-K. Hong, J. Park. Comput. Condens. Matter 1, 45 (2014).

[32] С.В. Труханов, А.В. Труханов, В.Г. Костишин, Л.В. Панина, И.С. Казакевич, В.А. Турченко, В.В. Кочервинский. Письма в ЖЭТФ 103, 106 (2016).

[33] S.M. El-Sayed, T.M. Meaz, M.A. Amer, H.A. El Shersaby. Physica B 426, 137 (2013).

[34] С.В. Труханов, А.В. Труханов, А.Н. Васильев, Г. Шимчак. ЖЭТФ 138, 236 (2010).

[35] V.G. Kostishyn, L.V. Panina, L.V. Kozhitov, A.V. Timofeev, A.N. Kovalev. J. Alloy Compd. 645, 297 (2015). 